\title{
An exploration of EFL learners' perceptions of classroom activities and their achievement goal orientations
}

\author{
Ghanizadeh, Afsaneh \\ Imam Reza International University, Mashhad, Iran (ghanizadeafsane@yahoo.com) \\ Jahedizadeh, Safoura \\ Imam Reza International University, Mashhad, Iran (Jahedi.s1310@gmail.com)
}

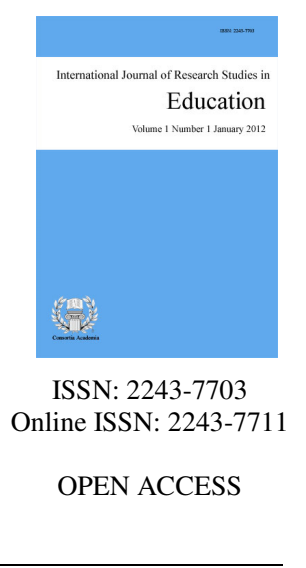

\section{Abstract}

The present paper delved into EFL students' perceptions of their classroom activities. To do so, a two-phase study was designed. The first phase included an array of different steps to validate the Persian version of the 'Students Perceptions of Classroom Activities' scale among 'English as a foreign language' (EFL) students. The scale measures four perceptions: interest, challenge, choice, and joy. In the second phase, we utilized the validated questionnaire along with an achievement-associated instrument to explore the relationship between EFL students' perceptions of their classroom activities and their achievement goal-orientations. The latter scale measures three achievement goals, namely, mastery, performance, and avoidance. The results of confirmatory factor analysis (CFA) and reliability estimates demonstrated the acceptable validity and reliability indices. The findings of the second phase attested to the hypothesized association between students' perceptions of classroom activities and their goal-orientations. The highest correlation was obtained between mastery goal and interest; the lowest correlation was observed between avoidance goal and joy.

Keywords: classroom perceptions; goal-orientation; EFL learners; CFA; correlation 


\section{An exploration of EFL learners' perceptions of classroom activities and their achievement goal orientations}

\section{Introduction}

Perception is the process by which we receive and interpret information from the world around us. The world consists of various levels and kinds of physical energy. Our knowledge of the world comes through our sense organs, which react to these energies. Various factors influence what and how we perceive. Our perceptions are influenced by the ways our bodies are structured to receive and process stimuli from the environment. These perceptions also reflect our emotions, expectations, learning and needs. Teachers' and students' views about the perceptions of classroom activities are significant areas to consider when designing effective educational experiences. Finding ways to increase the effectiveness of student learning is very important as well. Students' motivation is affected by classroom climate: the combined intellectual, emotional, physical and social environments in which students learn. If students perceive the environment as supportive and feel heard and included, their motivation will be enhanced.

On the other hand, if students perceive the environment as unsupportive or feel marginalized, it may erode their motivation to engage with the material or even to continue in the field. The students' perceptions consist of four main parts; interest, choice, challenge and joy. Each of these tenets plays a crucial role in perceptions students get from their classroom environment. The very nature of classes, teaching and students, make the classroom climate a critical ingredient of student success (Doyle, 2006). Teachers create both the psychological and social environments for learning. As a consequence, teachers who spend more time for learning or involve more students and help them to become self-regulated can establish an effective classroom climate.

Many studies have shown the importance of teachers' perceptions of their classroom environment. For instance, Mucherah and Frazier in 2013 conducted a research to have a look into high school biology classes in Kenya to find the relation between teachers' perceptions of classroom and students' goal orientations. They found that male teachers perceive themselves to be more innovative and supportive, but observers found female classes more innovative and well-organized and this resulted in significant differences in students' goal-orientation. Other studies focused on the relationship between students' perceptions of classroom activities and some other variables. For example, it is claimed that student and teacher gender, ethnic background, students' age, teaching experience, class size, student achievement and subject are factors which affect students' perception of classroom environment.

Another example is a study conducted by Gentry, Gable, and Rizza in 2002 among middle and elementary students. Their study demonstrated that female elementary students perceive their class activities more frequently enjoyable and interesting than male middle students. As a result, grade-level and gender differences contribute to various perceptions of classroom climate perceived by students. These perceptions can also affect students' motivation and use of self-regulating strategies. Teacher support and involvement are also salient features of students' perceptions (Lee, Yin, \& Zhang, 2009). The same topic with a different context was used to conduct the research among Iranian high school students by Kharrazi and Kareshki in 2010. The data analysis showed that relations between self-regulated learning and environmental perceptions are affected by motivational beliefs. Research has also revealed that students' perceptions of their teachers' interpersonal behavior is an important factor in explaining their affective and cognitive outcomes (Brok, Brekelmans, \& Wubbels, 2004).

Young (1997) used a longitudinal design to examine the relations among cognitive strategy use, motivational orientation, and classroom perceptions over time and found a significant relationship among these three variables. He also claimed that one aspect of classroom environment is the subject area. For instance, 
An exploration of EFL learners' perceptions of classroom activities and their achievement goal orientations

secondary math is static, hierarchical and clearly defined than English, Science or Social studies (Grossman \& Stodolsky, 1995). A conceptual model of relationships among constructivist learning environment perceptions, epistemological beliefs and learning approaches was proposed by Ozkal, Tekkaya, Cakiroglu, and Sunsur in 2008. Based on this study, constructivism focuses on students' understanding which means that the learner constructs his/ her own knowledge by relating new information to the old one. Such a classroom is learner-centered, inductive, interactive, and collaborative. Epistemological beliefs involve learners' theories about the nature of the knowledge, knowledge acquisition, and knowing. Learning approaches in general indicate two views; rote or surface and meaningful or deep learning. Students have some preferences over using one or both of these approaches.

According to this study, Ozkal et al. (2008) found that all constructivists learning environment predict learning approach, but the relation between fixed beliefs and learning approach is not significant. While, Hardré and Sullivan (2007) contended that teacher support, peer support, and teachers' interpersonal styles shape the students' perception of classroom environment; and these perceptions strongly predict perceptions of competence and instrumentality of the goal orientations as well as the content. To empirically examine the Hardré and Sullivan's (2007) contention, the present research focuses on the hypothesized role of students' perceptions of classroom environment in shaping their perceptions of educational goals, i.e., achievement goal orientation.

The theory behind the achievement goal revolves around how students think about themselves, their performance and their tasks in the classroom. Achievement goal theory focuses on students' perception of educational goals. At the outset of the achievement goal introduction (Ames, 1992; Dweck \& Leggett, 1988), a two factor model of achievement goals comprising two goal orientations, namely, mastery and performance goal orientations was proposed. A mastery goal signifies a standpoint in which students are concerned with developing their competence or mastering a task. Contrarily, a performance goal represents a view in which learners are concerned with displaying their competence relative to others.

Later in 1999, Elliot conducting a meta- analysis on goal-orientation literature, made a prominent distinction in Dweck's original definition of a performance goal. In particular, Dweck viewed performance goals in the light of either trying to approach desirable judgments and demonstrating competence compared to others versus trying to avoid unfavorable judgments and representing incompetence compared to others. Hence, Elliot conceptualized performance goals in terms of performance-approach and performance-avoidance goals (Elliot \& Harackiewicz, 1996). In this way, they proposed a three factor model of achievement goals consisting of mastery, performance-approach, and performance-avoidance goals. A performance-approach goal was defined as attempting to demonstrate competence relative to others, while performance-avoidance goal was defined as attempting to avoid incompetence relative to others. This distinction was readily embraced by educational scholars on the grounds that it contributed to a better account for the pattern of contradictory relationships between performance goals and diverse adaptive and maladaptive outcomes. Specifically, performance-approach goals were related to endeavor, persistence, competitiveness, and high scores, whereas performance-avoidance goals were connected to test anxiety, low self-efficacy, and low grades (Elliot \& McGregor, 2001).

The inclusion of an avoidance dimension to performance goal inspired the scholars in the domain of achievement goal to see if it can be applied to mastery goal as well. Thus, in 2001, Elliot and McGregor, based on several lines of reasoning, added a fourth goal to the achievement goal framework: mastery-avoidance which is defined as "an emphasis on desisting self-referential or task-referential incompetence" (Elliot, 2005, p. 61). An example of a person adapting mastery goals in the academic domain is a student who focuses on avoiding misunderstanding class material. According to Elliot (2005), this addition to the achievement goal framework was explained by perceiving achievement goals as a function of two key historical perspectives involving an individual's definition of competence (i.e., how individuals assess their competence) and valence toward competence (i.e., Individuals' tendency to focus on approaching versus eluding). 
Elliot (2005) further claimed that individuals could define their success or failure in fulfilling the need for competence in three ways. The first is absolute competence, which implies the competence according to the ability to complete a specific task (i.e., task referential). The second is intrapersonal competence, which is defined as the competence based on developing one's past performance on a task (i.e., self-referential). The third is interpersonal competence, which means the competence relative to others (i.e., other-referential). A mastery goal orientation would be reflective of holding an absolute or intrapersonal definition of competence, whereas a performance goal would be reflective of maintaining an interpersonal definition of competence. Individuals can also have different capacities: approaching competence versus avoiding incompetence. For example, an individual could approach seeking to develop task performance (i.e., a mastery-approach goal), or s/he could focus on trying not to perform poorly on a task (i.e., a mastery-avoidance goal).

In the present study, the Elliot's (1997) tripartite model of achievement goal-orientation is utilized. As stated earlier, according to this model, there are three types of achievement goal orientations; 1) mastery goals, 2) performance-approach goals, and 3) performance avoidance goals (Elliot, 1999). These classifications are elaborated in more details:

$>$ Mastery goals: these goals signify a standpoint in which individuals focus on developing their competence or by improving and developing their ability against self-set standards. By competence, researchers mean absolute and intrapersonal ones, which the first alludes to defining competence based on the capability to fulfill a particular task (i.e., task referential) and the second is based on improving one's past performance on a task (i.e., self-referential). Mastery-oriented learners face challenges and persevere in difficulties (Dweck, 2000). They use elaboration strategies, are intrinsically motivated and as a result attain high levels of performance (Elliot \& Dweck, 1998). There are adaptive and effective patterns of achievement and learning associated with mastery goals (Pajares, Britner, \& Valiante, 2000). Students who believe that ability is defined by effort tend to adopt mastery goals (Nichols, 1990).

$>$ Performance-approach goals: learners are concerned about displaying their ability which means individuals strive to demonstrate their competence relative to others (Elliot \& Harackiewicz, 1996). Performance-oriented students use superficial learning strategies and are extrinsically motivated (Elliot \& Dweck, 1988). On the other hand, Wolters, Yu, and Pintrich (1996) argued that these students show adaptive learning patterns including deep regulatory and cognitive strategies. Those who believe that ability is determined by normative comparison but not effort, tend to adopt performance goals. Dweck's genuine definition of a performance goal is when students try to approach desirable judgments and display competence compared to others. This competence is interpersonal which is relative to others (i.e., other-referential).

$>$ Performance avoidance goals: the main concern of students having such goals is hiding their lack of ability (Elliot, 1999). They use maladaptive learning patterns and try to avoid unfavorable judgments and demonstrating incompetence compared to others. i.e., it is defined as striving to avoid incompetence relative to others. Elliot and McGrengor (2001) specified that while performance-approach goals are linked to persistence, competitiveness, effort and high scores, performance-avoidance goals are linked to low self-efficacy, anxiety and low grades in tests.

A study by Roebken (2007) revealed that learners who pursue both mastery and performance- approach goals achieve better grades, show a higher degree of academic engagement and are more satisfied with the academic experience compared with learners pursuing performance-avoidance orientation or even a mastery or performance-approach alone. A plethora of studies conducted in the realm of achievement goal orientation and other variables. Jackson (2002) and Pajares (2003), for example, found a positive relationship between the types of goals individuals have in their learning and their efficacy beliefs. They indicated that students with mastery goals have higher self-efficacy than those with performance-approach or avoidance orientation. 
An exploration of EFL learners' perceptions of classroom activities and their achievement goal orientations

Another study conducted by Dweck and Leggett (1998) depicted that individuals adapting a mastery orientation have higher perception of self-efficacy and self-confidence. Consequently, they are more successful in their courses than students with goals other than mastery ones. Pintrich and DeGroot (1990) in a study to find the relationship between goal-orientation and cognitive and metacognitive strategies indicated those students selecting mastery goals use more cognitive and metacognitive strategies than learners who just focus on proving themselves and their capabilities to others or avoiding others to have an unfavorable judgment.

Eighteen years later, Kharazi, Ezhehei, Ghazi Tabatabaei, and Karrshki (2008) reported significant correlations between achievement goals, self-efficacy and metacognition components in the context of Iran and reported similar results as Pintrich and DeGroot did in 1990. Huang (2011) aimed at examining correlations between achievement goals and achievement emotions. The results indicated that mastery goals correlated highly with interest and enjoyment rather than anxiety. Another study conducted by Hulleman, Schrager, Bodmann, and Harackiewicz (2010) corroborated the findings of the previous study. They found positive correlations between mastery goals and interest. Church, Elliot, and Gable (2001) conducted a study to find the relationship between students' perception of classroom environment, their achievement goals, performance and intrinsic motivation.

The results indicated that perceived classroom environment influences achievement goals students adopt and these goals directly influence their performance and intrinsic motivation. Dickinson (1995) found that individuals with positive perceptions of classroom or school environment enhance their learning and motivation by adapting mastery goals. As it can be seen, some studies have been conducted to find the relationship between students' perception of classroom environment and achievement goal orientation, but there is no evidence to substantiate this relation among Iranian EFL learners across three different contexts (high school, university, and private institute).

\subsection{Purpose of the study}

The main purpose of the present study is to explore the EFL learners' perceptions of classroom activities by examining the role of these perceptions in shaping their educational goals, i.e., achievement goal orientation. In so doing, this study was designed in two phases. In phase one, the student's perceptions of classroom activities scale was translated into Persian. It was then administered to a group of Iranian EFL learners to determine its validity and internal consistency. The second phase of the study employed the validated scale along with another translated scale measuring goal orientations in order to investigate the relationship between EFL learners' perceptions of classroom activities and their achievement goal orientation.

\subsection{Method}

Participants - The participants of the present study comprised 250 EFL learners (142 female, 108 male) selected according to convenience sampling among EFL students learning English in 3 different contexts (official, semi-official, and non-official) in Mashhad, a city in north east of Iran. After a brief explanation of the purpose of the research, all participants received the translated questionnaire (Persian version of student's perceptions of classroom activities scale) in order to determine its reliability and validity. To gather reliable data, the researchers assured the participants that their views would be confidential by asking them not to write their names. They were just required to indicate demographic information such as, age, gender, average, major, educational and proficiency level. The questionnaires were coded numerically. Having validated the instrument, in the second phase of the study, the researchers asked the same respondents to complete another questionnaire measuring their goal orientations.

The profile of the participants is as follows: Their age varied from 12 to 52 years old ( $M=19.8, S D=5.02)$, with the average between 12.5 and $20(M=17.14, S D=1.84)$ and different proficiency levels varied from elementary to advance. Out of 250 students, 78 were learning English at the third level of high school as an obligatory course, 79 were university students studying three different majors of English (15 ELT students, 28 
Ghanizadeh, A., \& Jahedizadeh, S.

translation students, and 30 literature students) and 93 were students studying English in Language Institutes. 37 participants did not mention their age, 82 students did not indicate their GPA, 28 learners did not indicate their proficiency level, and 6 participants did not specify their major. There were no requirements other than that the participants be currently studying an English course during November and December of 2014.

\subsection{Instruments}

Students' Perceptions of Classroom Environment - To determine students' perceptions about their classroom, the researchers translated 'Students Perceptions of Classroom Activities' scale designed and validated by Gentry and Gable (2001) to Persian and made minor modifications regarding the content of some items in order to be used in the context of Iran. The 'Students Perceptions of Classroom Activities' instrument contains 31 statements evaluating four dimensions (interest, challenge, choice, and enjoyment). The scale measures the four dimensions via a 5-point Likert-type response format (never, seldom, sometimes, often, and always). The questionnaire provided the participants with directions on how to complete the scale. As reported by Gentry, Gable, and Rizza (2002), the instrument was piloted and a confirmatory study was undertaken for a national sample. Validity evidence for construct interpretation was investigated through confirmatory factor analysis. A GFI of .95 and a RMSEA of .04 were indicative model fit. Item response theory was used to examine the adequacy of the definition of each construct including how well the 5-point frequency response scale worked for the items and respondents.

Sample items for 'interest' dimension included: 1) The teacher involves me in interesting learning activities; and 2) What I do in my class gives me interesting and new ideas. Sample items for 'challenge' dimension are: 1) I have to think to solve problems in my class, and 2) What we do in class fits my abilities. Sample items included in 'choice' dimension are: 1) When we work together, I can choose my partners, and 2) When there are many jobs, I can choose the ones that suit me. Sample items for 'joy' dimension are: 1) The teacher makes learning fun, and 2) I like what I do in my class.

Achievement Goal Orientation Inventory - Students' goal orientation was measured by the translated version of Achievement Goal Orientation Inventory designed by Midgley et al. (1998). The inventory comprises three subscales, 6 items for each goal orientation and a total of 18 items, and it allows responses ranging from 1 (not at all true of me) to 7 (very true of me). Table 1 represents three possible goal orientations as follows:

Table 1

Subscales of the AGOI along with the Corresponding Descriptions

\begin{tabular}{llc}
\hline \multicolumn{1}{c}{ Subscale } & \multicolumn{1}{c}{ Definition } & Alpha/Items \\
\hline Mastery-approach & $\begin{array}{l}\text { Attaining task-based or intrapersonal } \\
\text { competence }\end{array}$ & $.85 / 1-6$ \\
Performance-approach & Attaining normative competence & $.89 / 7-12$ \\
Performance-avoidance & Avoiding normative incompetence & $.74 / 13-18$ \\
\hline
\end{tabular}

The Persian version of the scale- translated and validated by Rezaee and Kareshki (2012) - demonstrated acceptable reliability indices $(.81, .89, .83$, respectively). The results of confirmatory factor analysis confirmed the validity of the translated version $(\mathrm{GFI}=.92, \mathrm{AGFI}=.88$, RMSEA=.07). In the present study, the reliability indices computed via Cronbach's alpha were found to be as follows: mastery $=.75$, performance $=.72$, and avoidance $=.71$.

\section{Results}

\subsection{Phase 1}

The first phase of the present study included an array of different steps to validate the translated version of 
An exploration of EFL learners' perceptions of classroom activities and their achievement goal orientations

the 'Students Perceptions of Classroom Activities' scale. Having translated the scale into Persian, a group of experts (a psychometrician and three English educators) evaluated the quality of items in terms of clarity and comprehensiveness. Accommodating the experts' views and subsequent revision resulted in a more refined and comprehensible version of the scale. The translated questionnaire was then administered to 250 EFL students.

To determine the validity of the scale, a confirmatory factor analysis (CFA) utilizing the LISREL 8.50 statistical package was performed. The model consisted of the four perceptions, namely, interest, challenge, choice, and joy. Interest comprised 8 items, challenge consisted of 9 items, choice included 7 items, and joy comprised 7 items. A number of fit indices were examined to evaluate the model fit: the chi square/df ratio which should be lower than 2 or 3, the normed fit index (NFI) and the good fit index (GFI) with the cut value greater than .90, and the root mean square error of approximation (RMSEA) of about .06 or .08 (Schreiber, Amaury, Stage, Barlow, \& King, 2006). The structural model is presented in Figure1. As indicated by Figure 1, the chi-square/df ratio (2.38) and the RMSEA (.062) reached the acceptable fit thresholds. The other two fit indices (GFI=.78 and NFI=.85) did not meet the acceptable fit thresholds but are slightly below those thresholds. According to Tseng, Dörnyei, and Schmitt (2006), in structural models it is normal for some indices to not conform to the majority trend. Overall, it can be concluded that the proposed model had a moderately good fit with the empirical data.

The indices on the lines indicate the standardized estimates and $t$-values, respectively. The first one is the standardized coefficient $(\beta)$ which demonstrates the factor loading of each item with respect to the corresponding factor and presents an easily grasped picture of effect size. The closer the magnitude to 1.0, the higher the correlation and the greater the factor loading of the item is. The magnitude of lower than 0.30 is an indication of weak factor loading; in such cases the item must be revised or discarded. The second measure is the $t$-value $(\mathrm{t})$; if $t>2$ or $t<-2$, we call the result statistically significant. As the figure demonstrates, all items had accepted factor loading.

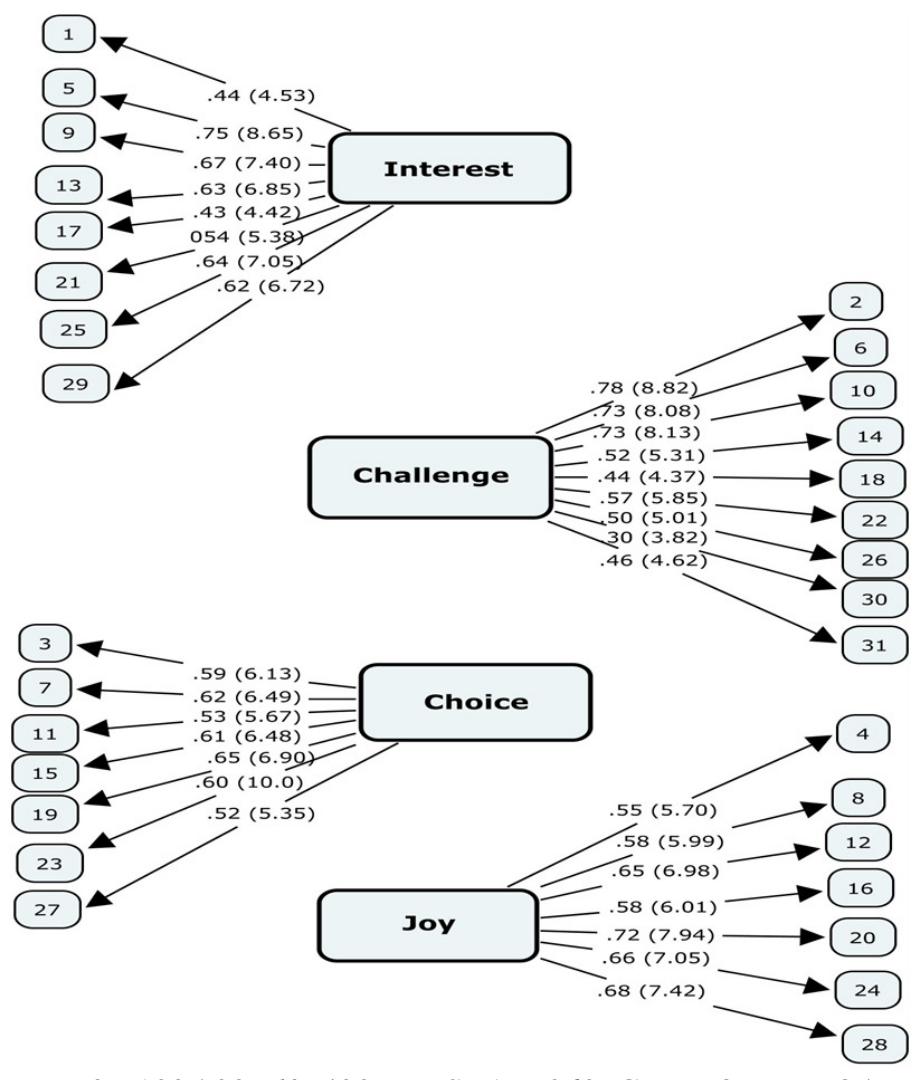

$\chi 2=1025.99, d f=429, \mathrm{RMSEA}=.062, \mathrm{GFI}=.78, \mathrm{NFI}=.85$

Figure 1. The schematic representation of the 4 perceptions and the corresponding items

The Cronbach's alpha estimates for each perception ranged from .71 to .80 . (interest $=.86$, challenge $=.73$, choice $=.71$, joy $=.79$ ). 
Ghanizadeh, A., \& Jahedizadeh, S.

The correlations among the four dimensions were then computed. As indicated in Table 2, the highest correlations were found between interest and joy $(\mathrm{r}=0.84, p<0.05)$, followed by the correlation between challenge and choice $(\mathrm{r}=0.70, p<0.05)$.

Table 2

The Correlation Coefficients among Factors of Classroom Perceptions

\begin{tabular}{lllll}
\hline & \multicolumn{1}{c}{$\mathbf{1}$} & \multicolumn{1}{c}{$\mathbf{2}$} & \multicolumn{1}{c}{$\mathbf{3}$} & \multicolumn{1}{c}{$\mathbf{4}$} \\
\hline 1. Interest & 1.00 & & & \\
2. Challenge & $.543^{* *}$ & 1.00 & & \\
3. Choice & $.612^{* *}$ & $.706^{* *}$ & 1.00 & \\
4. Joy & $.840^{* *}$ & $.399^{* *}$ & $.514^{* *}$ & 1.00 \\
\hline
\end{tabular}

Note. ${ }^{*} *$ Correlation is significant at the 0.05 level

\subsection{Phase 2}

In the second phase of the present study, we examined the relationship between students' perceptions of classroom activities (interest, challenge, choice, and joy) and their achievement goal-orientations (mastery, performance, avoidance). Table 3 represents the descriptive statistics of the four perceptions goals. As table shows, among the four perceptions, challenge and interest had the highest means respectively, interest $(M=31$, $S D=4.60)$, challenge $(M=32, S D=5.06)$.

Table 3

Descriptive Statistics of Students' Perceptions of Classroom Activities

\begin{tabular}{lccccc}
\hline & $n$ & Minimum & Maximum & Mean & $S D$ \\
\hline INT & 236 & 12.00 & 40.00 & 31.1144 & 4.60338 \\
CHA & 235 & 14.00 & 42.00 & 31.9149 & 5.16741 \\
CHO & 232 & 7.00 & 32.00 & 25.5474 & 4.32324 \\
JOY & 235 & 7.00 & 35.00 & 27.4213 & 4.13413 \\
\hline
\end{tabular}

Table 4 presents the descriptive statistics of the three goals. According to the table, performance and mastery goals had the almost equal means: performance $(M=24.47, S D=3.35)$, mastery $(M=24.50, S D=3.63)$. Avoidance had a lower mean as follows: $(M=23.80, S D=3.78)$.

\section{Table 4}

Descriptive Statistics of Students' Goal Orientations

\begin{tabular}{lccccc}
\hline & $n$ & Minimum & Maximum & Mean & $S D$ \\
\hline MG & 244 & 11.00 & 30.00 & 24.4713 & 3.35720 \\
PG & 241 & 10.00 & 30.00 & 24.5062 & 3.63676 \\
AG & 241 & 10.00 & 30.00 & 23.8050 & 3.78805 \\
\hline
\end{tabular}

To investigate the relationship between perceptions of classroom activities and goal orientation, multiple correlations were run. The results of Pearson Product Moment correlations are presented in Table 5.

\section{Table 5}

The Correlation Coefficients among Perceptions of Classroom Activities and Goal-orientations

\begin{tabular}{|c|c|c|c|c|c|c|}
\hline & 1 & 2 & 3 & 4 & 5 & 6 \\
\hline 1. Mastery & 1.00 & & & & & \\
\hline 2. Performance & $.226 * *$ & 1.00 & & & & \\
\hline 3. Avoidance & $.171 * *$ & $.333 * *$ & 1.00 & & & \\
\hline 4. Interest & $.627 * *$ & $.262 * *$ & $.231 * *$ & 1.00 & & \\
\hline 5. Challenge & $.458 * *$ & $.276 * *$ & $.393 * *$ & $.543 * *$ & 1.00 & \\
\hline 6. Choice & $.476 * *$ & $.228 * *$ & $.280 * *$ & $.612 * *$ & $.706 * *$ & 1.00 \\
\hline
\end{tabular}

Note. ${ }^{*} *$ Correlation is significant at the level of 0.05 
An exploration of EFL learners' perceptions of classroom activities and their achievement goal orientations

As indicated in the Table, the highest correlations were found between mastery goal and interest $(r=0.627$, $p<0.05)$ and between mastery goal and joy $(r=0.594, p<0.05)$. The lowest correlation was detected between avoidance goal and joy $(r=0.199, p<0.05)$.

\section{Discussion}

The primary aim of the present study was to validate the Gentry, et al.'s (2002) scale measuring students' perceptions of classroom activities in an EFL context and among Iranian students. To do so, the scale was translated into Persian and was administered to Iranian EFL students. The results of CFA and reliability estimates demonstrated that the scale had good model fit with the empirical data. In other words, the translated version of the scale enjoyed acceptable validity and reliability indices. To see how the four dimensions of the scale (interest, challenge, choice, and joy) converge with each other, a correlation analysis was run. The results indicated that the highest correlations were found between interest and joy, followed by the correlation between challenge and choice. It is accepted that, interest motivates the learner through increasing cognitive functioning, attention, affective involvement and persistence. As a result, learners who perceive their classroom activities as interesting enjoy the environment as well. On the other hand, students who have more opportunities to choose (e.g., the type of term project) in their classroom and are more involved in the activities perceive the environment more engrossing and challenging. These findings can be interpreted as a plausible indication of further validation of the scale.

The second purpose of this study was to utilize the validated questionnaire to explore the relationship between EFL students' perceptions of their classroom activities and their achievement goal-orientations. According to the results of correlation analysis, the highest correlation was observed between mastery goal and interest. In other words, EFL students who exhibited higher interest in their classes were more inclined towards attaining intrapersonal competence. The aforementioned finding is in line with the previous empirical studies. Pekrun, Reinhard, Elliot, Andrew, Maier, and Markus (2009), for instance, found that achievement goals (mastery, performance approach, and performance avoidance) predict discrete achievement emotions (enjoyment, anger, hope, pride, boredom anxiety, shame, and hopelessness). These emotions shape students' perception regarding classroom activities. Viewing from another perspective, we can argue that being interested in a topic leads to better achievement and performance. In other words, interest is a process which contributes to learning (Hidi, 1990).

Indeed, interest promotes effort, attention, recall, and achievement (Ainley, Hidi, \&Berndorff, 2002; Hidi \& Renninger, 2006). Dickinson (1995) found that individuals with positive perceptions of classroom or school environment enhance their learning and motivation by adapting mastery goals.Shen, Chen, and Guan (2007) conducted a study to find the extent to which achievement goals and interest influence in-class physical activity. The moderate correlation between mastery goals and interest suggested that, mastery goals had a significant influence on the recognition of interest in the classroom. In their study, students with high mastery goals were more interested in doing activities and consequently were more involved in doing tasks in physical education. Other researchers have also suggested that mastery goals are significantly related to adaptive and positive motivational patterns such as interest (McGregor \& Elliot, 2002).

Harackiewicz and Hulleman (2010) did a longitudinal study to highlight the role of achievement goals and task values in promoting the development of interest. They mentioned when learners enter into a classroom, they adapt goals which are specific to that situation. The students may want to meet new people, get a good grade, impress their friends, avoid being unfavorably judged, or learn something interesting. The goals individuals choose provide reasons and purposes to engage in classroom activities. As a particular relevance to interest development, a student who is interested in the topic, activity or classroom environment, focuses on task mastery and skill development which consequently encourage the learner to explore all aspects of an activity and adapt a mastery-goal orientation to develop the skills (Flum \& Kaplan, 2006). 
Huang (2011) aimed at examining the nexus between achievement goals and achievement emotions. The results indicated that mastery goals correlated highly with interest and enjoyment rather than anxiety. Church, Elliot, and Gable (2001) conducted a study to find the relationship between students' perception of classroom environment, their performance and intrinsic motivation. The results depicted that perceived classroom environment influences achievement goals students adopt and these goals directly influence their performance and intrinsic motivation. In their study, students with positive perceptions specially interest, were more apt at pursuing their competence by developing and improving their ability against self-set standards. In a similar vein, Hulleman, Schrager, Bodmann, and Harackiewicz (2010) found positive association between effective and adaptive patterns of learning (a characteristic of mastery goal) and interest. Taken together, according to the results of this phase of the study and as supported by other researchers, it can plausibly be concluded that, if students perceive the environment as supportive and feel heard and included, their motivation would be enhanced and consequently they will adapt a mastery goal orientation.

On the other hand, the lowest correlation was observed between avoidance goal and joy. In other words, EFL learners with lower joy regarding their classes were more concerned about not being unfavorably judged and not indicating incompetency relative to others. Avoidance goal orientation has been found to be detrimental to learning and achievement. Murayama, Kou, Elliot, and Andrew (2012) conducted a meta-analytic review to find the relation between competition and performance. They stated that, competition prompts performance-approach goals which facilitate performance and performance-avoidance goals which undermine performance. Furthermore, it is accepted that one of the most important factors affecting students' perception and adapting goal orientation is the teacher. Consequently, it is crucial for teachers to assist learners in not adapting performance-avoidance goal orientations, for example by not putting emphasis on students' grades which engender avoidance goals. If students perceive the environment as unsupportive, boring, useless, and feel marginalized in the classroom, it may erode their motivation to engage with the material or even continue in the field. In this situation, individuals will adapt performance-avoidance goal orientation.

The low correlation between avoidance-goal orientation and joy is in line with other empirical studies. Kaplan, Gheen, and Midgley (2002) found that the classrooms with an emphasis on performance-avoidance goals were associated with disruptive behaviors. Such behaviors have various reasons among which lack of students' joy regarding the activities done in the classroom plays a vital role especially among EFL learners. Students with different goals have various perceptions of the classroom activities. If they are intrinsically motivated and choose mastery goal orientation in their learning they would have positive perceptions about their classroom. In contrast, if students are extrinsically motivated and have low mastery goals in their learning, they would have negative perceptions through their classroom environment. Hence, as it can be seen, the relationship between students' perceptions of classroom activities and their achievement goal orientation is reciprocal in which both of them influence each other. As a result, it is crucial for EFL teachers to know how to improve positive perceptions in students and help the learners adapt mastery or at least performance-approach goals.

\subsection{Implication of the study}

Results of this study, in accordance with previous research regarding students' perceptions of classroom activities, revealed that these perceptions specify learners' goal orientations which shape their conceptualization toward their learning environment. If students perceive their classroom activities as challenging, interesting, and joyful with various options to choose a particular task, their first priority would be adapting mastery goal orientation, i. e., they desire to learn a foreign language for enhancing their knowledge, not for the sake of getting good marks or being judged incompetent relative to others. On the other hand, learners who perceive their classroom activities as unsupportive, not demanding, and boring with fewer opportunities to opt their favorite task would adapt a performance-avoidance goal orientation toward their EFL learning. On the other hand, it was found that students' goal orientations affect their perceptions of classroom activities. Students with mastery goal orientations would have positive perceptions toward their classroom activities, while performance-avoidance learners perceive their classroom activities negatively. 
An exploration of EFL learners' perceptions of classroom activities and their achievement goal orientations

One of the prominent roles of EFL teachers is to enhance learning outcomes and help students adapt good habits toward learning environment by adapting mastery goals. Teachers in an EFL context can shape these perceptions by providing challenging activities, interesting tasks with vast ranges of options, and enjoyable learning environment. Designing such activities need time, energy, cost, motivation, and support of educational authorities, but the point is that it's worth doing. Although, making all EFL learners interested in learning process is a tough job, it is possible to lead students toward mastery goal orientation by emphasizing on their proficiency in learning, not their marks at the end of the course. The implications mentioned here are totally practical if the ultimate objective of motivated teachers is to ameliorate students' functionality rather than superficial learning of the course.

\section{References}

Ainley, M., Hidi, S., \& Berndorff, D. (2002).Interest, learning, and the psychological processes that mediate their relationship. Journal of Educational Psychology, 94, 545-561. http://dx.doi.org/10.1037/0022-0663.94.3.545

Ames, C. (1992). Classrooms: Goals, structures, and student motivation. Journal of Educational Psychology, 84, 261-271. http://dx.doi.org/10.1037/0022-0663.84.3.261

Brok, P., Brekelmans, M., \& Wubbels, T. (2004).Interpersonal teacher behaviour and student outcomes. School Effectiveness and School Improvement, 15, 407-442. http://dx.doi.org/10.1080/09243450512331383262

Church, M. A., Elliot, A. J., \& Gable, S. A. (2001).Perceptions of classroom environment, achievement goals, and achievement outcomes. Journal of Educational Psychology, 93(1), 43-54. http://dx.doi.org/10.1037/0022-0663.93.1.43

Dickinson, L. (1995). Autonomy and motivation: A literature review. System, 23(2), 165-174. http://dx.doi.org/10.1016/0346-251X(95)00005-5

Doyle, W. (2006). Ecological approaches to classroom management. In C. M. Evertson \& C.S. Weinstein (Eds.), Handbook for classroom management: Research, practice, and contemporary issues (pp. 97-125). London: Lawrence Erlbaum Associates.

Dweck, C. S. (2000). Self-theories: Their role in motivation, personality, and development. Lillington, NC: Taylor \& Francis.

Dweck, C. S., \& Leggett, E. L. (1988).A social-cognitive approach to motivation and personality. Psychological Review, 95, 256-73. http://dx.doi.org/10.1037/0033-295X.95.2.256

Elliot, A. (1999). Approach and avoidance motivation and achievement goals. Educational Psychologist, 34, 149-169. http://dx.doi.org/10.1207/s15326985ep3403_3

Elliot, A. J. (2005). A conceptual history of the achievement goal construct. In A. J. Elliot \& C. S. Dweck (Eds.) Handbook of Competence and Motivation (pp. 52-72). New York, New York: The Guilford Press.

Elliott, E. S., \& Dweck, C. (1988). Goals: An approach to motivation and achievement. Journal of Personality and Social Psychology, 54, 5-12. http://dx.doi.org/10.1037/0022-3514.54.1.5

Elliot, A. J., \& Harackiewicz, J. M. (1996). Approach and avoidance achievement goals and intrinsic motivation: a mediational analysis. Journal of Personality and Social Psychology, 70(3), 461-475. http://dx.doi.org/10.1037/0022-3514.70.3.461

Elliot, A. J., \& McGregor, H. A. (2001). A 2 X2 achievement goal framework. Journal of Personality and Social Psychology, 80,501-519. http://dx.doi.org/10.1037/0022-3514.80.3.501

Flum, H., \& Kaplan, A. (2006).Exploratory orientation as an educational goal. Educational Psychologist, 41, 99-110. http://dx.doi.org/10.1207/s15326985ep4102_3

Gentry, M., \& Gable, R. K. (2001).My class activities: A survey instrument to assess students' perceptions of interest, challenge, choice, and enjoyment in their classrooms. Mansfield Center, CT: Creative Learning Press.

Gentry, M., Gable, R., \& Rizza, M. (2002). Students' perceptions of classroom activities: Are there grade-Level and gender differences? Journal of Educational Psychology, 94(3), 539-544. 
Ghanizadeh, A., \& Jahedizadeh, S.

http://dx.doi.org/10.1037/0022-0663.94.3.539

Grossman, P. L., \& Stodolsky, S. S. (1995). Content as context: The role of school subjects in secondary school teaching. Educational Researcher, 24, 5-11. http://dx.doi.org/10.3102/0013189X024008005

Harackiewicz, J., \& Hulleman, S. (2010). The importance of interest: The role of achievement goals and task values in promoting the development of interest. Social and Personality Psychology Compass, 4(1), 42-52. http://dx.doi.org/10.1111/j.1751-9004.2009.00207.x

Hardré, P. L., \& Sullivan, D. W. (2007). Student differences and environment perceptions: How they contribute to student motivation in rural high schools. Learning and Individual Differences, 18, 471-485. http://dx.doi.org/10.1016/j.lindif.2007.11.010

Huang, C. (2011). Achievement goals and achievement emotions: A meta-analysis. Education Psychology Review, 23, 359-388. http://dx.doi.org/10.1007/s10648-011-9155-x

Hidi, S. (1990). Interest and its contribution as a mental resource for learning. Review of Educational Research, 60, 549-571. http://dx.doi.org/10.3102/00346543060004549

Hidi, S., \& Renninger, K. A. (2006).The four-phase model of interest development. Educational Psychologist, 41, 111-127. http://dx.doi.org/10.1207/s15326985ep4102_4

Hulleman, C. S., Schrager, S. M., Bodmann, S. M., \& Harackiewicz, J. M. (2010). A meta-analytic review of achievement goal measures: Different labels for the same constructs or different constructs with similar labels? Psychological Bulletin, 136, 422-449. http://dx.doi.org/10.1037/a0018947

Jackson, J. W. (2002). Enhancing self-efficacy and learning performance. The Journal of Experimental Education, 70, 243-55. http://dx.doi.org/10.1080/00220970209599508

Kaplan, A., Gheen, M., \& Midgley, C. (2002). Classroom goal structure and student disruptive behavior. British Journal of Educational Psychology, 72, 191-211. http://dx.doi.org/10.1348/000709902158847

Kharazi, S. A. N., Ezhehei, J., Ghazi Tabatabaei, M., \& Kareshki, H. (2008). An investigation of the relationships between achievement goals, self-efficacy and metacognitive strategies: Testing a causal model. Journal of Psychology and Education, 38, 69-87. http://dx.doi.org/10.1016/j.sbspro.2010.07.430

Kharrazi, A., \& Kareshki, H. (2010).Environmental perceptions, motivational beliefs and self-regulating learning by Iranian high school students. Proceedia Social and Behavioral Sciences, 5, 2160-2164.

Lee, J., Yin, H., \& Zhang, Z. (2009).Exploring the influence of the classroom environment on students' motivation and self-regulated learning in Hong Kong. The Asia-Pacific Education Researcher, 18(2), 219-232. http://dx.doi.org/10.3860/taper.v18i2.1324

McGregor, H. A., \& Elliot, A. J. (2002).Achievement goals as predictors of achievement relevant processes prior to task engagement, Journal of Educational Psychology, 94, 381-395. http://dx.doi.org/10.1037/0022-0663.94.2.381

Midgley, C., Kaplan, A., Middleton, M., Maehr, M. L., Urdan, T., Anderman, L. H., Anderman, E., \& Roeser, R. (1998).The development and validation of scales assessing students' achievement goal orientations. Contemporary Educational Psychology, 23(2), 113-131. http://dx.doi.org/10.1006/ceps.1998.0965

Mucherah, W., \& Frazier, A. (2013). How teachers perceive their classroom environments and student goal orientation: A look into high school biology classrooms in Kenya. British Journal of Education, Society \& Behavioural Science, 3(1), 1-17. http://dx.doi.org/10.9734/BJESBS/2013/2413

Murayama, K., \& Elliot, A. J. (2012). The competition-performance relation: a meta-analytic review and test of the opposing processes model of competition and performance. American Psychological Association, 138(6), 1035-1070.

Nicholls, J. G. (1990). What is ability and why are we mindful of it? A developmental perspective. In R.Sternberg \& J. Lolligian (Eds.), Competence considered (pp. 11-40). New Haven: Yale University Press.

Ozkal, K., Tekkaya, C., Cakiroglu, J., \& Sungur, S. (2008). A conceptual model of relationships among constructivist learning environment perceptions, epistemological beliefs, and learning approaches. Learning and Individual Differences, 19, 71-79. http://dx.doi.org/10.1016/j.lindif.2008.05.005

Pajares, F. (2003). Self-efficacy beliefs, motivation, and achievement in writing: A review of the literature. Reading and Writing Quarterly, 19, 139-158. http://dx.doi.org/10.1080/10573560308222 
An exploration of EFL learners' perceptions of classroom activities and their achievement goal orientations

Pajares, F., Britner, S., \&Valiante, G. (2000).Relation between achievement goals and self-beliefs of middle school students in writing and science. Contemporary Educational Psychology, 25, 406-422. http://dx.doi.org/10.1006/ceps.1999.1027

Pekrun, R., Elliot, A. J., \& Maier, M. (2009).Achievement goals and achievement emotions: Testing a model of their joint relations with academic performance. Journal of Educational Psychology, 101(1), 115-135. http://dx.doi.org/10.1037/a0013383

Pintrich, P. R., \& DeGroot, E. V. (1990).Motivational and self-regulated learning components of classroom academic performance. Journal of Educational Psychology, 82, 33-40. http://dx.doi.org/10.1037/0022-0663.82.1.33

Pulfrey, C., Buchs, C., \& Butera, F. (2011). Why grades engender performance-avoidance goals: The mediating role of autonomous motivation. Journal of Educational Psychology, 103(3), 638-700. http://dx.doi.org/10.1037/a0023911

Rezaee, M., \& Kareshki, K. (2012). A cross-comparison of achievement goal-orientations of Iranian and Afghani students. Paper presented at the 6th conference of university students' mental health. Gilan: Iran

Roebken, H. (2007). The influence of goal orientation on student satisfaction, academic engagement and achievement. Electronic Journal of Research in Educational Psychology, 5(3), 679-704.

Schreiber, J. B., Amaury, N., Stage, F. K., Barlow, E. A., \& King, J. (2006).Reporting structural equation modeling and confirmatory factor analysis results: A Review. Journal of Educational Research, 99(6), 323-337. http://dx.doi.org/10.3200/JOER.99.6.323-338

Shen, B., Chen, A., \& Guan, J. (2007).Using achievement goals and interest to predict learning in physical education.Journal of Experimental Education, 75(2), 89-108. http://dx.doi.org/10.3200/JEXE.75.2.89-108

Tseng, W. T., Dörnyei, Z., \& Schmitt, N. (2006). A new approach to assessing strategic learning: The case of self-regulation in vocabulary acquisition. Applied Linguistics, 27(1), 78-102. http://dx.doi.org/10.1093/applin/ami046

Wolters, C., Yu, S., \& Pintrich, P. (1996).The relation between goal orientation and students' motivational beliefs and self-regulated learning. Learning and Individual Differences, 8, 211-238. http://dx.doi.org/10.1016/S1041-6080(96)90015-1

Young, A. J. (1997). I think, therefore I'm motivated: the relations among cognitive strategy use, motivational orientation and classroom perceptions over time. Learning and Individual Differences, 9(3), 249-283. http://dx.doi.org/10.1016/S1041-6080(97)90009-1 
Ghanizadeh, A., \& Jahedizadeh, S. 